\title{
A Cluster Randomized Trial of Interventions to Improve Work Conditions and Clinician Burnout in Primary Care: Results from the Healthy Work Place (HWP) Study
}

\author{
Mark Linzer, $M D^{7,3}$, Sara Poplau, BA², Ellie Grossman, MD, MPH' , Anita Varkey, $M D^{5}$, \\ Steven Yale, $M D^{6}$, Eric Williams, $P h D^{7}$, Lanis Hicks, $P h D^{8}$, Roger L. Brown, PhD 9 , Jill Wallock, $B S^{5}$, \\ Diane Kohnhorst, $B S^{6}$, and Michael Barbouche, $B S^{10}$
}

\begin{abstract}
'Division of General Internal Medicine, Hennepin County Medical Center, Minneapolis, MN, USA; ${ }^{2}$ Minneapolis Medical Research Foundation, Minneapolis, MN, USA; ${ }^{3}$ University of Minnesota, Minneapolis, MN, USA; ${ }^{4}$ NYU School of Medicine, New York, NY, USA; ${ }^{5}$ Loyola University Medical

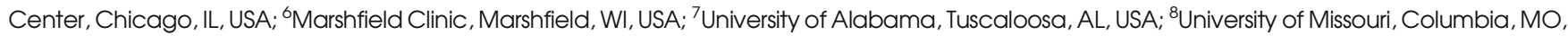
USA; 'University of Wisconsin School of Medicine and Public Health and School of Nursing, Madison, WI, USA; ${ }^{10}$ Forward Health Group, Inc., Madison, WI, USA.
\end{abstract}

BACKGROUND: Work conditions in primary care are associated with physician burnout and lower quality of care. OBJECTIVE: We aimed to assess if improvements in work conditions improve clinician stress and burnout.

SUBJECTS: Primary care clinicians at 34 clinics in the upper Midwest and New York City participated in the study.

STUDY DESIGN: This was a cluster randomized controlled trial.

MEASURES: Work conditions, such as time pressure, workplace chaos, and work control, as well as clinician outcomes, were measured at baseline and at 12-18 months. A brief worklife and work conditions summary measure was provided to staff and clinicians at intervention sites.

INTERVENTIONS: Diverse interventions were grouped into three categories: 1) improved communication; 2) changes in workflow, and 3) targeted quality improvement (QI) projects.

ANALYSIS: Multilevel regressions assessed impact of worklife data and interventions on clinician outcomes. A multilevel analysis then looked at clinicians whose outcome scores improved and determined types of interventions associated with improvement.

RESULTS: Of 166 clinicians, 135 (81.3\%) completed the study. While there was no group treatment effect of baseline data on clinician outcomes, more intervention clinicians showed improvements in burnout (21.8\% vs $7.1 \%$ less burned out, $p=0.01)$ and satisfaction $(23.1 \% \mathrm{vs}$ $10.0 \%$ more satisfied, $p=0.04$ ). Burnout was more likely to improve with workflow interventions [Odds Ratio (OR) of improvement in burnout 5.9, $p=0.02$ ], and with targeted QI projects than in controls (OR 4.8, $p=0.02$ ). Interventions in communication or workflow led to greater improvements in clinician satisfaction (OR 3.1, $p=0.04$ ), and showed a trend toward greater improvement in intention to leave (OR 4.2, $p=0.06$ ).

Presented in part at the Annual Meetings of the Society of General Internal Medicine, San Diego, CA, April 2014.

Received September 17, 2014

Revised November 26, 2014

Accepted February 3, 2015

Published online February 28, 2015
LIMITATIONS: We used heterogeneous intervention types, and were uncertain how well interventions were instituted.

CONCLUSIONS: Organizations may be able to improve burnout, dissatisfaction and retention by addressing communication and workflow, and initiating QI projects targeting clinician concerns.

KEY WORDS: burnout; primary care; quality improvement; work conditions.

J Gen Intern Med 30(8):1105-11

DOI: $10.1007 / \mathrm{s} 11606-015-3235-4$

(c) Society of General Internal Medicine 2015

\section{INTRODUCTION}

The context in which primary care is delivered is rarely evaluated as part of quality improvement initiatives or research studies. Often overlooked is the role of work conditions perceived by health care clinicians and the potential impact on clinicians and patients. ${ }^{1}$ A robust primary care workforce is needed in the wake of health care reform and the predicted marked increase in patients seeking primary care clinicians. ${ }^{2}$ Unfortunately, little attention has been paid to whether the US will be able to retain and recruit primary care clinicians impacted, in part, by the perception of work conditions expressed by current primary care practitioners. ${ }^{3}$

In the Physician Worklife Study (PWS) in 1996-2000, we demonstrated a high prevalence of stress and burnout, especially among women physicians and those who practiced primary care. We also showed that adverse work conditions were associated with an intention to leave the practice and perceptions of suboptimal patient care. ${ }^{1,4,5}$ The MEMO study (Minimizing Error, Maximizing Outcome) in 2001-2005 showed that work conditions in primary care were strongly associated with adverse physician outcomes, such as stress, burnout, dissatisfaction and intent to leave. ${ }^{6}$ MEMO also demonstrated that some patient outcomes were sensitive to primary care work conditions. ${ }^{6}$ Recent articles have called attention to the potential impact of physician burnout, ${ }^{7-10}$ 
and of the adverse consequences of electronic health records for busy clinicians. ${ }^{11,12}$ We devised the current study (Healthy Work Place study, or HWP) to test whether knowledge of clinician perceptions of the workplace would prompt conversations among clinic leaders, staff and clinicians, and lead to interventions to address work conditions and improve clinician outcomes. Future results from HWP will focus on whether patient outcomes were altered by these efforts.

We hypothesized that workplace changes, prompted by feedback on clinician perceptions and outcomes, would lead to a decrease in clinician stress and improved care for patients. This paper specifically addresses the following question: Does receipt of baseline data on work conditions and targeted clinical interventions improve satisfaction, stress, burnout and intent to leave the practice?

\section{METHODS}

Sample. We chose three study sites, two in the upper Midwest and one in New York City. The sites were selected to provide a mix of urban/rural/suburban and academic/non-academic locations. With site-specific Institutional Review Board (IRB) approval, we recruited 166 primary care clinicians (including general internists, family physicians, nurse practitioners and physician assistants) at 34 primary care clinics. Sample size calculations prior to initiating recruitment of clinicians determined that 34 clinics would provide sufficient power to address the study questions. Eligible clinicians included those who had been with the practice for at least 1 year at a minimum of 0.5 full time equivalent (FTE) weekly.

Study Design. We based our study upon the conceptual model highlighted in and refined after the MEMO project, ${ }^{6}$ with work conditions affecting clinician and patient outcomes (Fig. 1). We performed a cluster randomized control trial with the clinic as the unit of randomization, with 34 clinics randomized to an intervention versus a control arm. Randomization took place after clinics consented to participate. To maintain balance per site, a permuted block randomization scheme using 1:1 allocation to treatment/ control was used, providing a balance of clinics per site. Site 1 recruited ten clinics, site 2 recruited 14 clinics and site 3 recruited ten clinics. Measures were performed at baseline in both intervention and control clinics (see below for measure description). An office and worklife (OWL) two-page measure of worklife and work conditions ${ }^{6}$ was created using 1) clinician perceptions of work conditions, 2) clinician outcomes (stress, burnout, and intent to leave the practice), and 3) patient quality of care data. These summaries were presented at intervention clinics to clinicians, staff and clinical leaders.

Clinical and research staff met at each intervention site to discuss the data and a list of topics/interventions was generated and used to address adverse clinician work conditions.
Research staff facilitated discussion among clinicians and provided guidance on the type or approach of intervention(s) chosen. OWL worklife and work condition data were the basis for the discussions and the selected interventions. While clinical teams worked off a relatively small menu of proven interventions (drawn from the literature, such as ${ }^{13,14}$ ), intervention(s) chosen were customized at the individual clinic level and comprised a broad list of ways to address work conditions (Table 1). Twelve to eighteen months later, clinician and patient measures were repeated at all 34 clinics.

Measures. Work conditions and clinician reactions were measured using survey tools adapted from $\mathrm{MEMO}^{6}$ and the PWS. ${ }^{4,5}$ Managers were questioned about clinic structure (rooms, staffing), policies, finances and procedures. Clinicians were questioned about stress, ${ }^{15}$ burnout (a fiveitem scale, focusing primarily on emotional exhaustion, with a score of 3 or higher indicating burnout, ${ }^{16,17}$ intent to leave in 2 years, and satisfaction. ${ }^{4}$ They also provided perceptions of work conditions, including time pressure during visits, work control, emphasis on work home balance, chaotic environments, and organizational culture, such as alignment of values with their leaders. Patient data (up to eight patients with diabetes or hypertension per enrolled clinician) were also included on the OWL worklife and work condition summary. Patients were asked about their satisfaction with care ${ }^{18}$ and chart audits determined care quality. All data were averaged per site, bundled into the two-page summary measures and distributed to intervention site clinicians, staff and leaders.

Interventions. Intervention sites chose a variety of methods to improve worklife and clinician outcomes (see Table 1). Details of selected interventions include 1) scheduling standing monthly provider meetings focused on either a) worklife issues and personal challenges, or b) difficult patient care management issues; 2) off-loading nonessential tasks to nonphysician staff including hiring additional staff, having medical assistants (MAs) enter patient data into the EMR, altering workflow between MAs and appointment coordinators, and consistently pairing MAs and clinicians; 3 ) removing bottlenecks to care in patient rooms regarding medication reconciliation, vaccinations, and data entry; 4) reduced time pressure with plans for a future increase in primary care visit time from 15 to 20 minutes; 5) instituting a new prescription line to free up RN staff; 6) clerks instead of clinicians tracking forms and sending faxes; and 7) presenting OWL data as a platform to discuss issues within the department. After the study was completed, the initiatives were grouped into three categories: 1) improving communication especially among clinicians and staff; 2) changes in workflow; and 3) QI projects addressing clinician concerns. These categories were developed by convening a work group of healthcare professionals (two physicians, one nurse practitioner, one research assistant, and the project manager) who identified the theme of each 


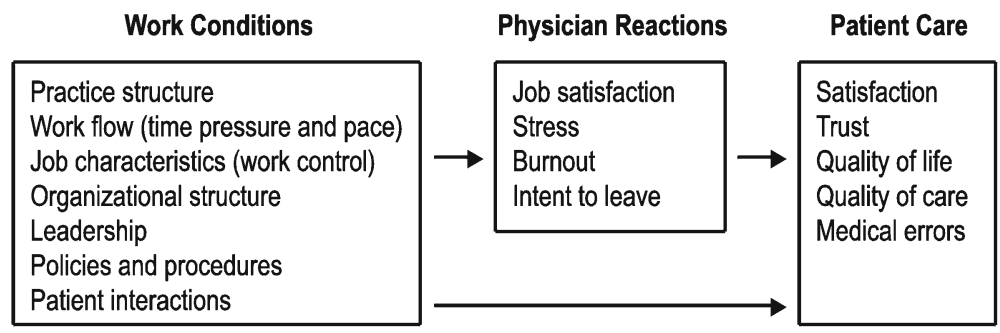

Figure 1. MEMO model of relationships between work conditions, clinician reactions and patient care. Adapted and used with permission from: Linzer M, Manwell LB, Williams ES, Bobula JA, Brown RL, Varkey AB, et al. Working conditions in primary care: physician reactions and care quality. Ann Intern Med. 2009;151:28-36.

intervention. These themes were eventually grouped into the three categories. "Improving communication" was a broad category that included provider-provider and provider-patient communication, obtaining better data and external marketing. Many clinics performed more than one type of intervention.

Analyses. Intra-class correlations (ICCs) were assessed for the four primary outcomes to determine dependency (impact of clustering). Two level regression analyses with clinicians nested within clinics assessed a post intervention group effect on group averages of clinician outcomes controlling for clinician age, gender, specialty and baseline clinician scores. A second two-level logistic regression analysis (person centered) then assessed any improvement change from baseline of intervention versus control clinicians, controlling for the covariates of age, gender, specialty, and years in practice. When a treatment effect was seen, an additional hierarchical logistic regression model was used to determine specific types of interventions associated with improvement. This analysis assessed different treatment configurations (e.g., improved communication versus workflow changes versus control), controlling for age, gender, specialty, and years in practice, This analytic framework has been proposed by others ${ }^{19}$ to assess the impact of treatments on subjects (in this case, clinicians), rather than the impact of treatments on measures.

\section{RESULTS}

Within 34 clinics, 166 clinicians were recruited into the study. One hundred and thirty-five clinicians at 32 clinics completed the project ( $81.3 \%$ of clinicians and $94.1 \%$ of clinics). Table 2 describes clinicians in intervention versus control clinics by specialty, gender, age, percent physicians (versus nurse practitioners or physician assistants), discipline, and baseline and final outcome data, including stress, burnout, satisfaction and likelihood to leave the practice. A relatively small proportion $(13.3 \%)$ of the sample was comprised of non-physicians (nurse practitioners and physician assistants.) Burnout was present at a somewhat higher rate in intervention clinics, $41.4 \%$ versus $30.1 \%$ in controls ( $p=0.12$ ). While dependency

Table 1. List of Representative Interventions in Healthy Work Places Study by Category

\begin{tabular}{|c|c|c|c|}
\hline$\overline{\text { Communications }}$ & Workflow & Targeted quality improvement (QI) & Other \\
\hline $\begin{array}{l}\text { Improved interpersonal } \\
\text { communication and teamwork }\end{array}$ & Utilize MA to enter data into EHR & $\begin{array}{l}\text { Establish quality metrics for } \\
\text { injections and mammograms }\end{array}$ & $\begin{array}{l}\text { Dashboard patient population } \\
\text { measures for clinicians }\end{array}$ \\
\hline $\begin{array}{l}\text { Improved communication } \\
\text { among providers }\end{array}$ & Better patient flow through the clinic & $\begin{array}{l}\text { New automated prescription line, } \\
\text { freeing time for nurses }\end{array}$ & $\begin{array}{l}\text { OWL data presentation (to } \\
\text { prompt discussions on } \\
\text { changing the clinic } \\
\text { environment) }\end{array}$ \\
\hline $\begin{array}{l}\text { Monthly clinician meetings } \\
\text { (formal discussions on patient care) } \\
\text { to improve collegiality }\end{array}$ & $\begin{array}{l}\text { Sharing information to make } \\
\text { clinic more efficient }\end{array}$ & Medication reconciliation project & \\
\hline $\begin{array}{l}\text { Informal survey of clinicians for a } \\
\text { 'wish list' of identified issues }\end{array}$ & $\begin{array}{l}\text { Assess workflow between } \\
\text { MAs and nurses }\end{array}$ & $\begin{array}{l}\text { Project to improve ophthalmology } \\
\text { and podiatry screening in diabetics }\end{array}$ & \\
\hline $\begin{array}{l}\text { Monthly email from firm leaders } \\
\text { with systems updates }\end{array}$ & $\begin{array}{l}\text { More time for nursing/MA } \\
\text { staff to complete tasks }\end{array}$ & $\begin{array}{l}\text { Examination of hypoglycemic } \\
\text { events and associated medications }\end{array}$ & \\
\hline \multirow{2}{*}{$\begin{array}{l}\text { Clinicians meeting individually } \\
\text { with leadership to review schedules } \\
\text { and identify concerns }\end{array}$} & Pairing one MA with each attending & Initiation of depression screening & \\
\hline & $\begin{array}{l}\text { Nurse coordinator providing } \\
\text { oversight for patient issues } \\
\text { Call schedule changed to share call } \\
\text { Planned increase in time for return visit } \\
\text { from } 15 \text { to } 20 \text { minutes } \\
\text { Staff support with patient forms }\end{array}$ & PDSA program for patient portals & \\
\hline
\end{tabular}


Table 2. Characteristics of HWP Clinicians in Intervention Versus Control Sites

\begin{tabular}{|c|c|c|c|c|c|c|}
\hline & \multicolumn{3}{|l|}{ Pre-intervention } & \multicolumn{3}{|c|}{ Post-intervention } \\
\hline & $\begin{array}{l}\text { Control group } \\
N=83\end{array}$ & $\begin{array}{l}\text { Intervention } \\
\text { group } N=\mathbf{8 3}\end{array}$ & $p$ value & $\begin{array}{l}\text { Control } \\
\text { group } N=72\end{array}$ & $\begin{array}{l}\text { Intervention } \\
\text { group } N=67\end{array}$ & $p$ value \\
\hline Age & $46.4(9.4)$ & $48.3(8.9)$ & 0.18 & $48.4(9.5)$ & $49.9(8.7)$ & 0.33 \\
\hline Duration in practices & $11.6(8.7)$ & $14.1(8.9)$ & 0.07 & $\mathrm{a}$ & $\mathrm{a}$ & \\
\hline Gender (males) & $49.4 \%(n=41)$ & $46.9 \%(n=39)$ & 0.75 & $47.8 \%(n=34)$ & $44.6 \%(n=29)$ & 0.64 \\
\hline Ethnicity (\% non-white) & $20.7 \%(n=17)$ & $12.0 \%(n=10)$ & 0.14 & a & a & \\
\hline Discipline (\% GIM) & $65.0 \%(n=54)$ & $55.4 \%(n=46)$ & 0.20 & $\mathrm{a}$ & $\mathrm{a}$ & \\
\hline Physicians (\%) & $90.3 \%(n=83)$ & $83.1 \%(n=83)$ & 0.16 & $\mathrm{a}$ & $\mathrm{a}$ & \\
\hline $\begin{array}{l}\text { High work control } \\
\text { (3 and greater)* }\end{array}$ & $13.2 \%(n=83)$ & $9.6 \%(n=83)$ & 0.46 & $11.4 \%(n=70)$ & $4.6 \%(n=65)$ & 0.14 \\
\hline $\begin{array}{l}\text { High satisfaction } \\
\text { (4 and greater) })^{* *}\end{array}$ & $51.8 \%(n=83)$ & $38.5 \%(n=83)$ & 0.08 & $45.7 \%(n=70)$ & $40.0 \%(n=65)$ & 0.50 \\
\hline High stress (4 and greater)** & $27.7 \%(n=83)$ & $30.1 \%(n=83)$ & 0.73 & $24.2 \%(n=70)$ & $30.7 \%(n=65)$ & 0.39 \\
\hline Burnout (3 and greater) $* * *$ & $30.1 \%(n=83)$ & $41.4 \%(n=82)$ & 0.12 & $32.8 \%(n=70)$ & $33.8 \%(n=65)$ & 0.90 \\
\hline Chaos ( 4 and greater) $)^{* *}$ & $45.5 \%(n=79)$ & $56.9 \%(n=79)$ & 0.15 & $54.4 \%(n=68)$ & $55.3 \%(n=65)$ & 0.91 \\
\hline $\begin{array}{l}\text { Likelihood to leave in } \\
2 \text { years ( } 3 \text { and greater)** }\end{array}$ & $17.0 \%(n=82)$ & $31.7 \%(n=82)$ & 0.03 & $22.3 \%(n=67)$ & $29.0 \%(n=62)$ & 0.38 \\
\hline
\end{tabular}

${ }^{a}$ Not collected post-intervention

* On a four-point scale, with 1 being low and 4 being high

** Scored on a five-point scale, with 1 being low and 5 being high

*** Question is scored using a five-point scale, with 3 being showing symptoms of burn out and 5 being completely burned out

was found to be minimal due to ICCs $<0.11$, with design effects $<2$, this was still controlled for within the hierarchical models.
All intervention site leaders reported that presentation and assessment of baseline worklife and work condition data facilitated important conversations about the work environment.
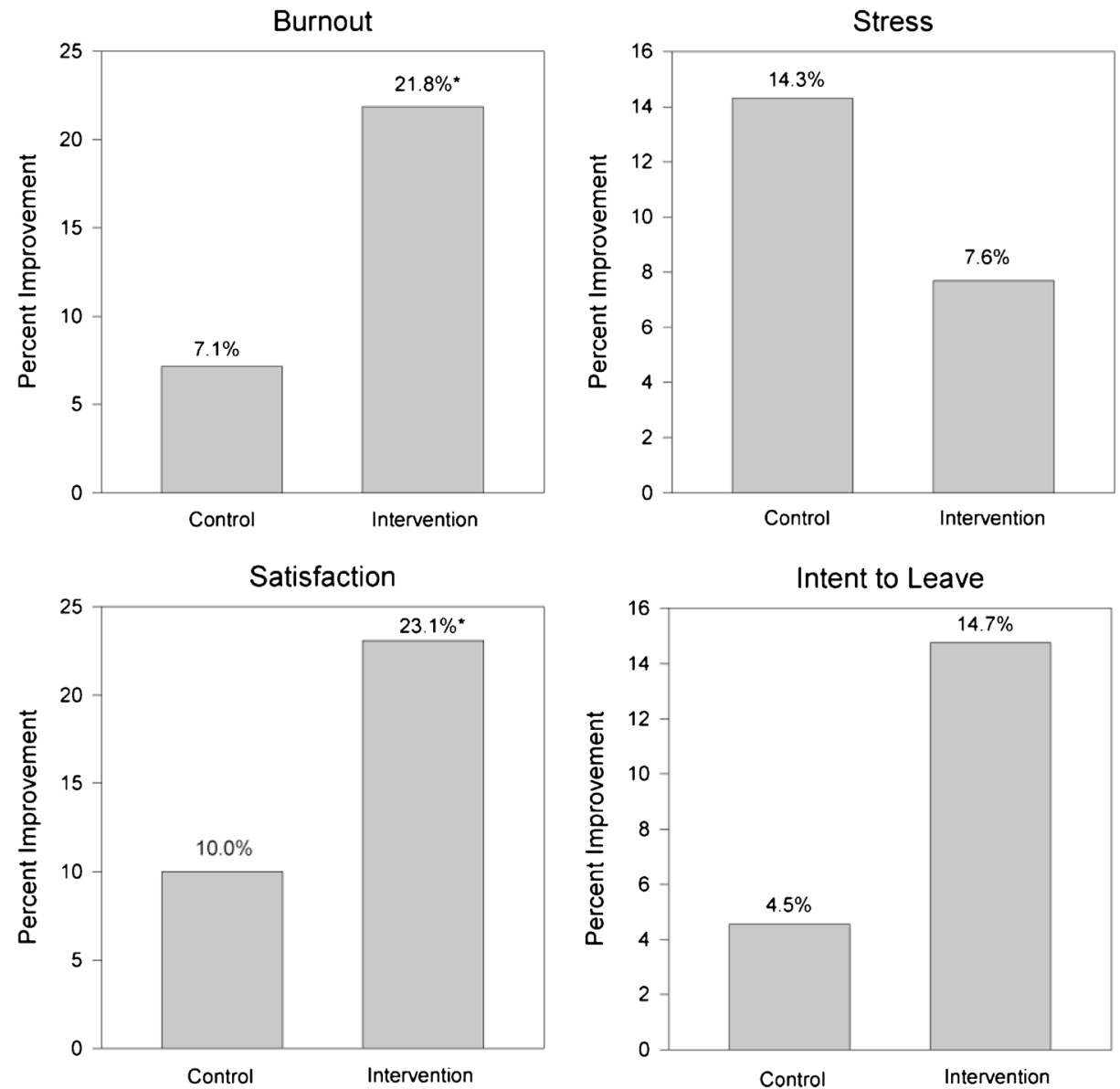

Figure 2. Percent of HWP clinicians showing improvement in burnout, stress, satisfaction and intention to leave in intervention versus control clinics. * $p<0.05$. 
Table 3. Multilevel Logistic Regression Analysis of Clinician Improvement by Specific Intervention Type: Control Clinics Versus 1) Communication Improvement and 2) Workflow Change Clinics

\begin{tabular}{|c|c|c|c|c|c|c|c|c|c|c|c|c|}
\hline & \multicolumn{3}{|c|}{ Improvement in burnout } & \multicolumn{3}{|c|}{ Improvement in stress } & \multicolumn{3}{|c|}{ Improvement in satisfaction } & \multicolumn{3}{|c|}{$\begin{array}{l}\text { Improvement in Intent } \\
\text { to Leave }\end{array}$} \\
\hline & $\begin{array}{l}\text { Odds } \\
\text { Ratio } \\
\text { (se) }\end{array}$ & $p$ value & $95 \%$ CI & $\begin{array}{l}\text { Odds } \\
\text { Ratio } \\
\text { (se) }\end{array}$ & $p$ value & $95 \%$ CI & $\begin{array}{l}\text { Odds } \\
\text { Ratio } \\
\text { (se) }\end{array}$ & $p$ value & $95 \%$ CI & $\begin{array}{l}\text { Odds } \\
\text { Ratio } \\
\text { (se) }\end{array}$ & $p$ value & $95 \%$ CI \\
\hline $\begin{array}{l}\text { Communication } \\
\text { emphasis } \\
(n=10)\end{array}$ & $3.0(1.8)$ & 0.08 & $(0.9,9.94)$ & $0.6(0.4)$ & 0.44 & $(0.2,2.2)$ & $3.6(2.2)$ & 0.04 & $(1.1,12.0)$ & $3.6(2.7)$ & 0.08 & $(0.8,15.5)$ \\
\hline $\begin{array}{l}\text { Workflow } \\
\text { changes } \\
(n=6)\end{array}$ & $5.9(4.3)$ & 0.02 & $(1.4,24.6)$ & $0.3(0.3)$ & 0.27 & $(0.03,2.6)$ & $1.6(1.3)$ & 0.52 & $(0.4,7.5)$ & $2.7(2.6)$ & 0.30 & $(0.4,18.1)$ \\
\hline
\end{tabular}

Controlling for age, gender and practice type

Table 2 shows that burnout decreased from 41.4 to $33.8 \%$ (a relative decrease of $17.6 \%$ ) in intervention clinicians, while burnout increased from 30.1 to $32.8 \%$ in control clinicians (an increase of $8.9 \%$ ). The initial multivariable modeling assessing the impact on clinician outcomes of OWL worklife and work condition data feedback and of the heterogeneous interventions at all intervention clinics combined did not disclose a group treatment effect. However, the person-centered improvement analysis showed significant treatment effects, with burnout decreasing more often in intervention clinicians (21.8\% fewer clinicians burned out vs $7.1 \%$ fewer control clinicians, $p=0.01$, see Fig. 2). There were no significant differences in improvements in stress and intention to leave between intervention and control clinics. Satisfaction improved more often after the interventions $(23.1 \%$ of clinicians were more satisfied in intervention clinics versus $10.0 \%$ in controls, $p=0.04$ ).

Clinicians in clinics performing workflow interventions were significantly more likely to have decreased burnout than those in control sites (OR of improvement in burnout in intervention clinics 5.9, $p=0.02$, see Tables 3 and 4). Clinicians in clinics performing targeted QI projects were also more likely to show decreases in burnout (OR of improvement $4.8 ; p=0.02$ ). Clinician satisfaction improved more often in clinics with interventions in communication or workflow than in controls (OR of improvement in satisfaction 3.1, $p=0.04$ ). Communication or workflow interventions also led to borderline improvements in intention to leave (OR 4.2, $p=0.06$ ): The models showed no appreciable change after incorporating a variable reflecting "professional status" (physician versus nurse practitioner or physician assistant).

\section{DISCUSSION}

In this cluster randomized controlled study of 166 clinicians in 34 clinics, we found that data on clinician work conditions facilitated discussions on the need to improve worklife for the benefit of patients and clinicians. Burnout was prevalent, and reported in approximately $37 \%$ of primary care clinicians. A significant effect on clinician outcomes was seen when assessing specific intervention types on individual clinicians. In particular, all three of the following types of interventions led to improvements in some clinician outcomes: 1) workflow redesign, 2) improved communication, especially among clinicians and staff, and 3) QI projects directed at clinician concerns. These data suggest that targeting a range of interventions to clinician perceptions can lead to improvements in meaningful clinician outcomes including burnout, dissatisfaction, and perhaps, retention.

Table 4. Separate Multilevel Logistic Regression Analysis of Clinician Improvement by Specific Intervention Type: Control Clinics Versus 1) Targeted QI Clinics and 2) Communication or Workflow Change Clinics

\begin{tabular}{|c|c|c|c|c|c|c|c|c|c|c|c|c|}
\hline & \multicolumn{3}{|c|}{ Improvement in burnout } & \multicolumn{3}{|c|}{ Improvement in stress } & \multicolumn{3}{|c|}{ Improvement in satisfaction } & \multicolumn{3}{|c|}{$\begin{array}{l}\text { Improvement in intent to } \\
\text { leave }\end{array}$} \\
\hline & $\begin{array}{l}\text { Odds } \\
\text { Ratio } \\
\text { (se) }\end{array}$ & $p$ value & $95 \%$ CI & $\begin{array}{l}\text { Odds } \\
\text { Ratio } \\
\text { (se) }\end{array}$ & $p$ value & $95 \% \mathrm{CI}$ & $\begin{array}{l}\text { Odds } \\
\text { Ratio } \\
\text { (se) }\end{array}$ & $p$ value & $95 \%$ CI & $\begin{array}{l}\text { Odds } \\
\text { Ratio } \\
\text { (se) }\end{array}$ & $p$ value & $95 \%$ CI \\
\hline $\begin{array}{l}\text { Quality } \\
\text { improvement } \\
\text { (QI) }(n=6)\end{array}$ & $4.8(3.2)$ & 0.02 & $(1.3,18.0)$ & $0.6(0.5)$ & 0.47 & $(0.1,2.8)$ & $2.4(1.6)$ & 0.17 & $(0.7,8.8)$ & $2.1(2.0)$ & 0.44 & $(0.3,13.5)$ \\
\hline $\begin{array}{l}\text { Communication } \\
\text { or workflow } \\
\text { emphasis } \\
(n=11)\end{array}$ & $3.0(1.9)$ & 0.08 & $(0.9,10.5)$ & $0.5(0.3)$ & 0.30 & $(0.1,1.9)$ & $3.1(1.7)$ & 0.04 & $(1.0,9.2)$ & $4.2(3.2)$ & 0.06 & $(1.0,18.3)$ \\
\hline
\end{tabular}

Controlling for age, gender and practice type 
There is little debate that the future of affordable and high quality care in America depends upon a large and dedicated primary care workforce. Current studies show that primary care clinicians are dissatisfied, not recommending the field to students, and in danger of leaving the field themselves. ${ }^{3}$ The current study addresses mechanisms for improving primary care work conditions, and may be the first to date that does so in a multi-center, randomized study design. Many issues have previously been identified that affect primary care clinicians, among them the electronic health record, ${ }^{11,12}$ inefficiencies in office practice, lack of teamwork, time pressure during office visits, ${ }^{6}$ a lack of control in the workplace, ${ }^{6}$ and a lack of career fit for time to do what one is most passionate about. ${ }^{20}$ Clinics serving minority patients have especially challenging work conditions, ${ }^{21}$ and primary care may be hardest to support where it is needed most.

The current study adds to this discussion, and begins to fill in knowledge gaps. Despite many warnings about burnout in primary care, our data show that burnout prevalence is high, and indeed is higher than in our prior studies, where it averaged $25-30 \%{ }^{6}$ Pressures for increasing patient volumes remain, and few administrators appear to have incorporated clinician wellness into institutional quality measures. ${ }^{22}$ If clinicians leave their practices, replacement costs may exceed $\$ 250,000 .^{23}$ These are among the many reasons for focusing on stress and burnout in primary care.

We propose that stress and burnout be measured and addressed as organizational quality metrics ${ }^{22}$; annual brief surveys may suffice, with more frequent measures in challenged clinics or departments. The current study provides data that demonstrate the potential power of new types of interventions in the workplace. There is emerging literature about interventions that individuals can undertake to better combat the tendency to burn out. ${ }^{24,25}$ Our study complements this work by showing that organizational change may also lead to reduced stress and improved clinician outcomes. Our most powerful intervention was workflow modification, such as reassigning clinic staff work and changing call schedules. Our next strongest intervention, championed by Dunn et al., ${ }^{13}$ was communication improvement, especially among staff and clinicians. (This involves, for example, conducting meetings focused on topics with meaning for clinicians, such as clinical cases and issues of clinic worklife.) Finally, we have demonstrated that there is potential value in targeting an organization's QI projects to clinician concerns. A wide range of QI programs was used, including automated prescription phone lines and establishing mechanisms to improve quality metrics for routine screening.

The interventions in the HWP project moved the clinics in both important and replicable directions. Communication projects resulting in improved communication among clinicians and staff instilled a culture of enhanced communication in the primary care setting. Workflow changes promoted the primary care team as a critical unit in improving clinician work. Finally, QI projects addressed achieving quality metrics, medication reconciliation and improved screening processes, areas that tend to be taxing for primary care clinicians.

There are limitations to our study, including the absence of an overall group treatment effect with receipt of OWL worklife and work condition data followed by an undifferentiated series of QI projects. However, a significant effect was seen with the individually focused analysis, especially within each of the three types of interventions. We suspect that the absence of an effect in the initial analysis may be due, in part, to the multiplicity or diversity of interventions. Future studies on the impact of the three intervention types are thus encouraged to confirm our results. Other limitations include the uncertainty as to how well or reproducibly the interventions might have been instituted, and whether a longer duration of follow-up might have provided a better sense of the impact of these workplace changes. There are numerous strengths to our study, including the rigorous study design, the geographic and clinical diversity of the three sites, and the use of previously validated, robust measures of clinician outcomes.

In summary, our data suggest that high burnout among primary care clinicians may be addressed by programs that measure clinician and patient outcomes, provide meaningful feedback to clinics, and modify workplaces via improvements in workflow and communication, or by using QI projects targeted to clinician concerns.

Acknowledgements: The project was supported by a grant from the Agency for Healthcare Research and Quality (AHRQ), Grant \# 5R18HSO18160-03.

Conflict of Interest: Dr. Hicks acknowledges royalties from a textbook. Mr. Barbouche is CEO of Forward Health Group, owns stock and has patents pending. There are no other conflicts of interest.

Corresponding Author: Mark Linzer, MD; Division of General Internal MedicineHennepin County Medical Center, Minneapolis, MN, USA (e-mail: Mark.linzer@hcmed.org).

\section{REFERENCES}

1. Williams ES, Halbesleben JRB, Manwell L, et al. The effect of workplace stress and burnout on patient outcomes. In: Carayon P, ed. Handbook of Human Factors in Healthcare and Patient Safety. Mahwah: Erlbaum; 2011.

2. Reuben DB. Saving primary care. Am J Med. 2007;120(1):99-102.

3. Hauer KE, Durning SJ, Kernan WN, et al. Factors associated with medical students' career choices regarding internal medicine. JAMA. 2008;300(10):1154-64.

4. Konrad TR, Williams ES, Linzer M, for the SGIM Career Satisfaction Study Group (CSSG), et al. Measuring physician job satisfaction in a changing workplace and a challenging environment. Med Care. 1999;37:1174-82.

5. Pathman DE, Konrad TR, Williams ES, Scheckler WE, Linzer M, Douglas J. Physician job satisfaction, job dissatisfaction and physician turnover. J Fam Pract. 2002;51(7):e593.

6. Linzer M, Manwell LB, Williams ES, et al. Working conditions in primary care: physician reactions and care quality. Ann Intern Med. 2009;151:28-36.

7. Dyrbye LN, Varkey P, Boone SL, Satele DV, Sloan JA, Shanafelt TD. Physician satisfaction and burnout at different career stages. Mayo Clin Proc. 2013;88:1358-67.

8. Spinelli WM. The phantom limb of the triple aim. Mayo Clin Proc. 2013;88:1356-7.

9. Brown S, Gunderman RB. Enhancing the professional fulfillment of physicians. Acad Med. 2006;81:577-82. 
10. Dyrbye LN, West CP, Satele D, Sloan JA, Shanafelt TD. Work/home conflict and burnout among academic internal medicine physicians. Arch Intern Med. 2011;171:1207-9.

11. Sinsky CA, Beasley JW, Simmons GE, Baron RJ. Electronic health records: design, implementation, and policy for higher-value primary care. Ann Intern Med. 2014;160:727-9.

12. Babbott $\mathbf{S}$, Baier $\mathbf{L}$, Linzer $\mathbf{M}$, et al. Electronic health records and physician stress in office based practice. JAMIA. 2013;0:1-7.

13. Dunn PM, Arnetz BB, Christensen JF, Homer L. Meeting the imperative to improve physician well-being: assessment of an innovative program. J Gen Intern Med. 2007;22(11):1544-52.

14. Reid RJ, Fishman PA, Yu O, et al. Patient-Centered Medical Home demonstration: a prospective, quasi-experimental, before and after evaluation. Am J Manag Care. 2009; 15(9):e71-87.

15. Motowidlo SJ, Packard JS, Manning MR. Occupational stress: its causes and consequences for job performance. J Appl Psychol. 1986;71:618-29.

16. Rohland BM, Kruse GR, Rohrer JE. Validation of a single-item measure of burnout against the Maslach Burnout Inventory among physicians. Stress Health. 2004;20(2):75-9.

17. Schmoldt RA, Freeborn DK, Klevit HD. Physician burnout: recommendations for HMO managers. HMO Pract. 1994;8:58-63.
18. Haas JS, Cook EF, Puopolo AL, Burstin HR, Cleary PD, Brennan TA. Is the professional satisfaction of general internists associated with patient satisfaction? J Gen Intern Med. 2000;15(2):122-8.

19. Kraemer HC, Fran E, Kupfer DJ. How to assess the clinical impact of treatments on patients, rather than the statistical impact of treatments on measures. Int J Methods Psychiatr Res. 2001;20(2):63-72.

20. Shanafelt TD, West CP, Sloan JA, et al. Career fit and burnout among academic faculty. Arch Intern Med. 2009;169(10):990-5.

21. Varkey AB, Manwell LB, Williams ES, et al. Separate and unequal: clinics where minority and nonminority patients receive primary care. Arch Intern Med. 2009; 169(3):243-50.

22. Wallace JE, Lemaire JB, Ghali WA. Physician wellness: a missing quality indicator. Lancet. 2009;374:1714-21.

23. Buchbinder SB, Wilson M, Melick CF, Powe NR. Estimates of costs of primary care physician turnover. Am J Manag Care. 1999;5:1431-8.

24. West CP, Dyrbye LN, Rabatin JT, et al. Intervention to promote physician well-being, job satisfaction and professionalism: a randomized clinical trial. JAMA Intern Med. 2014;174:527-33.

25. Beckman HB, Wendland $\mathbf{M}$, Mooney $\mathbf{C}$, et al. The impact of a program in mindful communication on primary care physicians. Acad Med 2012;87:815-9 